\title{
Risk factors of intrauterine fetal death: a case control study at the maternity of Yaoundé Central Hospital
}

\author{
Romaric Joel Tetsiguia Momo ${ }^{1}$, Jeanne Hortence Fouedjio ${ }^{1 *}$, Florent Ymélé Fouelifack ${ }^{2}$, \\ Robinson Enow Mbu' ${ }^{1}$
}

\begin{abstract}
${ }^{1}$ Department of Obstetrics and Gynecology, Faculty of Medicine and Biomedical Sciences, University of Yaoundé I, Cameroon

${ }^{2}$ Department of Obstetrics and Gynecology, Higher Institute of Medical Technology Nkolondom, University of Douala, Cameroon
\end{abstract}

Received: 26 March 2019

Accepted: 06 May 2019

\section{*Correspondence:}

Dr. Jeanne Hortence Fouedjio,

E-mail: fouedjiojeanne@yahoo.fr

Copyright: () the author(s), publisher and licensee Medip Academy. This is an open-access article distributed under the terms of the Creative Commons Attribution Non-Commercial License, which permits unrestricted non-commercial use, distribution, and reproduction in any medium, provided the original work is properly cited.

\section{ABSTRACT}

Background: Intrauterine fetal death (IUFD) is the death before the beginning of the work of the fetus from the 28th week of pregnancy or a fetus of weight greater than or equal to $1000 \mathrm{~g}$. It occurs in $98 \%$ in poor countries, particularly in sub-Saharan Africa. The aim of this study was to identify the risk factors for IUFD in low-income countries.

Methods: All the women with preeclampsia from 30 weeks onwards were enrolled in the study. The umblical artery (UA) Systolic-diastolic (S/D) ratio >2 standard deviation (SD) or UA-pulsatility index (PI) and UA-resistive index (RI) >2 SD were taken as abnormal. The middle cerebral artery (MCA) was visualised and cerebroumblical PI ratio calculated. MCA-RI $<2$ SD was taken as abnormal.

Results: Independent risk factors for IUFD are age over 30 years $(\mathrm{ORa}=2.1, \mathrm{P}=0.052),(\mathrm{ORa}=2.4497, \mathrm{p}=0.01)$, household occupation $(\mathrm{ORa}=2.0097, \mathrm{p}=0.0282)$, hypertension disorders $(\mathrm{ORa}=2.11, \mathrm{p}=0.0176)$, antepartal haemorrhage $(\mathrm{ORa}=3.9635, \mathrm{p}=0.000)$, multiparity $(\mathrm{ORa}=13.3089, \mathrm{p}=0.0056)$.

Conclusions: The main risk factors for IUFD identified in our study are maternal age greater than 30 years, hypertension, antepartal haemorrhage, multiparity, and the household profession. Any pregnant woman who has one of these factors should be follow-up closely during pregnancy with a weekly assessment of fetal well-being by the $28^{\text {th }}$ week.

Keywords: Fetal death, Intrauterine, Risk factors, Ultrasound, Yaoundé

\section{INTRODUCTION}

According to the WHO, fetal death in utero is fetal death after the $22^{\text {nd }}$ week or for a weight greater than $500 \mathrm{~g}$. In Cameroon, the threshold for fetal death in utero is 28 weeks or more than $1000 \mathrm{~g}$. In 2015 , an estimated 2.6 million MFIU worldwide, $33 \%$ of which before the start of work. ${ }^{1,2}$ Most of these deaths, $98 \%$, occur in low- and middle-income countries, particularly in sub-Saharan
Africa and Asia. ${ }^{1}$ The global prevalence of this event, estimated at $2 \%$, varies from one country to another. ${ }^{3} \mathrm{~A}$ study conducted in Madagascar found an annual incidence of $5.22 \% .^{4}$ Similarly Diallo et al, in Guinea found a prevalence of $6.95 \%$ at Conakry University Hospital. $^{5}$

Several risk factors related to MFIU have been highlighted regarding its etiopathogenesis in various studies. The most frequently identified risk factors are a 
high body mass index, maternal age above 35, smoking, high blood pressure in pregnancy. ${ }^{3}$ Placental involvement is most common in the etiopathogenesis of the occurrence of MFIU. ${ }^{6,7}$ Other causes are funicular abnormalities, maternal fetal hemorrhages, chromosomal, malformative and infectious abnormalities. ${ }^{3}$ The diagnosis of certainty is made on fetal ultrasound. In addition, the etiological diagnosis may require specific examinations such as fetal autopsy, pathological and infectious placental analysis, fetal karyotype analysis, or fetal MRI. ${ }^{3}$ This event is at the origin of many complications that can lead to maternal death. These complications are mainly chorioamionitis, postpartum hemorrhage by CIVD and retention of placental debris. ${ }^{8,9}$ It is also at the origin of a psychological stress in the framework of the taking charge of the current event, but also in front of the fear of the risk of recidivism. It concerns the patient and his entourage as well as the treatment personnel. ${ }^{10}$

An approach to fight this event involves the clinician's action on the risk factors and therefore the knowledge of the latter in his particular socio-economic and cultural environment. In Cameroon, few studies have been done on this subject to take into account factors specific to the social, cultural and economic particularities of this context.

Authors carried out this study which general objective was to identify the risk factors of IUFD at the maternity hospital of the central hospital of Yaounde. More specifically, to describe the socio-demographic characteristics, to determine the gyneco-obstetric profile, to describe the course of the pregnancy and to determine the characteristics of the fetuses.

\section{METHODS}

To achieve these objectives, we carried out a case-control study. The recruitment of the participants was done over a period of December 2016-January 2018 retrospectively from the medical records. The control group was recruited from ultrasound results. The study was conducted at the maternity of the central hospital of Yaoundé. We choose this maternity because it is one of biggest one in Yaoundé with an average of 300 births per month and the central hospital is a second category health facility according to the health system organization of Cameroun. The inclusion criteria were those patients who performed an ultrasound that confirmed the death of the fetus. We excluded cases that did not do any ultrasound before giving to birth. The study population was made up of the women who delivered in the maternity of the Yaoundé central hospital. The cases in our study consisted of patients whose fetuses had died in In utero. We considered fetal death in utero (IUFD) to be the death of the fetus from the $28^{\text {th }}$ week of pregnancy and before the beginning of labor. The controls were pregnant women whose fetuses were alive of the same gestational age as the case. For 1 case we recruited 4 controls.
The calculation of the sample size was done by the Schlesseman's formula which allow to obtain the size of 80 cases for 320 controls. Ethically, we obtained the consent of each participant in the study and the questionnaire used to collect the data was anonymous.

\section{Statistical analysis}

Data collection was carried out using a pre-tested questionnaire. We studied the socio-demographic characteristics, the gyneco-obstetrical profile, and the course of the pregnancy as well as the characteristics of the fetus at the expulsion or according to the ultrasound parameters.

The socio-demographic variables were the age, level of education, occupation and the marital status. The Gyneco-obstetric variables were the number of pregnancies (gravidity), number of deliveries at term (parity), history of IUFD, history of abortion. The variables for the course of pregnancy were the number of pre-natal consultation, antepartum hemorrhage, HIV infection, diabetes, sickle cell disease. For the fetus, the variables were: malformations, birth weight, sex, number of fetuses.

The data were collected using a form. The data was entered and analyzed using Epi info version 3.5.4. We used the Excel software to create the tables. We calculated the Odd ratio (OR) look for associations between variables with its $95 \%$ confidence interval. The statistically significant associations were integrated into a logistic regression model to identify independent risk factors. The value of $\mathrm{p}$ less than $5 \%$ was considered significant.

\section{RESULTS}

\section{The socio-demographic characteristics of the participants}

In our study population, age over 30 years, low educational level and housewife occupation were statistically associated with IUFD. Concerning the marital status, we find out that the most participants of our study were single without any association with IUFD (Table 1).

\section{The gyneco-obstetrical profile}

The gravidity $>5$ and parity $>5$ were statistically associated with IUFD. The history of abortion is more common in control group than in case group, we did not find any association between history of abortion and IUFD. The frequency of past history of IUFD in control group is greater than in case group without any difference statistically significant (Table 2). 


\section{The course of the pregnancy}

The number of antenatal care; Infections such as urinary tract infection, chorioamnionitis and HIV; diabetes; sickle cell are not associated with intrauterine demise.
Antepartum hemorrhage and hypertension disorders during pregnancy increase by 4.5 time and 2.78 time respectively the risk of IUFD are risk factors for IUFD (Table 3).

Table 1: Distribution of participants by sociodemographic characteristics.

\begin{tabular}{|lllll|}
\hline Variables & Case N=80 $(\%)$ & Control N=320 $(\%)$ & OR (IC 95\%) & P-value \\
\hline Age & & & & \\
\hline$\leq 20$ & $16(20)$ & $40(12.5)$ & $1.75(0.9-3.29)$ & 0.060 \\
\hline $21-25$ & $23(28.8)$ & $89(27.8)$ & $1.05(0.6-1.79)$ & 0.480 \\
\hline $26-30$ & $18(22.5)$ & $141(44.1)$ & $0.37(0.2-0.65)$ & 0.000 \\
\hline$\geq 30$ & $23(28.8)$ & $50(15.6)$ & $2.18(1.21-3.84)$ & 0.010 \\
\hline Level of education & & & $3.28(1.85-5.75)$ & 0.000 \\
\hline Primary & $27(33.8)$ & $43(13.4)$ & $1.27(0.77-2.08)$ & 0.200 \\
\hline secondary & $44(55)$ & $157(49.1)$ & $0.18(0.07-0.38)$ & 0.000 \\
\hline High & $7(8.8)$ & $112(35)$ & $1(0.14-4.43)$ & 0.630 \\
\hline None & $2(2.5)$ & $8(2.5)$ & $2.3(1.38-3.81)$ & 0.000 \\
\hline Occupation & & & $0.36(0.14-0.82)$ & 0.010 \\
\hline Housewives & $36(45)$ & $84(26.3)$ & $0.51(0.28-0.92)$ & 0.020 \\
\hline Civil servant & $6(7.5)$ & $59(18.4)$ & $0.65(0.19-1.81)$ & 0.310 \\
\hline Student & $16(20)$ & $105(32.8)$ & $1.65(0.88-3)$ & 0.080 \\
\hline Unemployment & $4(5)$ & $24(7.5)$ & $1.59(0.96-2.66)$ & 0.050 \\
\hline Autre & $18(22.5)$ & $48(15)$ & $0.67(0.4-1.11)$ & 0.070 \\
\hline Marital status & & & $0(0-3.29)$ & 0.330 \\
\hline Single & $51(63.8)$ & $168(52.5)$ & & \\
\hline Married & $29(36.3)$ & $147(45.9)$ & $5(1.6)$ & \\
\hline Widow & $0(0)$ & & \\
\hline
\end{tabular}

Table 2: Distribution of participants according to the gynecological-obstetric profile.

\begin{tabular}{|c|c|c|c|c|}
\hline Variables & Case $\mathrm{N}=\mathbf{8 0}$ n (\%) & Control N=320 n (\%) & OR (IC 95\%) & P-value \\
\hline \multicolumn{5}{|l|}{ Gravidity } \\
\hline 1 & $24(30)$ & $137(42.8)$ & $0.57(0.33-0.97)$ & 0.020 \\
\hline $2-3$ & $16(20)$ & $126(39.4)$ & $0.38(0.21-0.69)$ & 0.000 \\
\hline $4-5$ & $15(18.8)$ & $50(15.6)$ & $1.25(0.64-2.33)$ & 0.300 \\
\hline$>5$ & $25(31.3)$ & $7(2.2)$ & $20.32(8.52-52.25)$ & 0.000 \\
\hline \multicolumn{5}{|l|}{ Parity } \\
\hline 1 & $46(57.5)$ & $250(78.1)$ & $0.38(0.23-0.64)$ & 0.000 \\
\hline $2-3$ & $12(15)$ & $51(15.9)$ & $0.93(0.45-1.81)$ & 0.500 \\
\hline $4-5$ & $11(13.8)$ & $16(5)$ & $3.03(1.3-6.81)$ & 0.010 \\
\hline$>5$ & $11(13.8)$ & $3(0.9)$ & $16.85(4.79-76.15)$ & 0.000 \\
\hline \multicolumn{5}{|c|}{ History of abortion } \\
\hline Yes & $17(21.3)$ & $95(29.7)$ & \multirow{2}{*}{$0.64(0.35-1.14)$} & \multirow{2}{*}{0.080} \\
\hline No & $63(78.8)$ & $225(70.3)$ & & \\
\hline \multicolumn{5}{|c|}{ History of IUFD } \\
\hline Yes & $7(8.8)$ & $41(12.8)$ & \multirow{2}{*}{$0.65(0.26-1.46)$} & \multirow{2}{*}{0.210} \\
\hline No & $73(91.3)$ & $279(87.2)$ & & \\
\hline
\end{tabular}

\section{The characteristics of the fetuses}

Female fetuses were predominant in the two groups, but the sex of the fetus is not associated with IUFD. The frequency of multiple pregnancy was $5 \%$ in case group and $6.9 \%$ in control group, even though we did not find any association with intrauterine demise. The frequency of intrauterine growth restriction was $11.3 \%$ and 13.4 
respectively in case and control group without any association with IUFD. Although fetal malformations were more frequent in case group than in control group, the difference was not statistically significant (Table 4).

Table 3: Distribution of participants according to antenatal care and pathologies during pregnancy.

\begin{tabular}{|c|c|c|c|c|}
\hline Variables & Case $\mathrm{N}=\mathbf{8 0}$ n (\%) & Control N=320 n (\%) & OR (IC $95 \%$ ) & P value \\
\hline \multicolumn{5}{|c|}{ Number of antenatal care } \\
\hline 0 & $11(13.8)$ & $29(9.1)$ & $1.6(0.73-3.31)$ & 0.150 \\
\hline $1-2$ & $23(28.8)$ & $72(22.5)$ & $1.39(0.79-2.4)$ & 0.150 \\
\hline $3-4$ & $20(25)$ & $108(33.8)$ & $0.65(0.37-1.13)$ & 0.080 \\
\hline$\geq 4$ & $26(32.5)$ & $111(34.7)$ & $0.91(0.53-1.52)$ & 0.410 \\
\hline \multicolumn{5}{|c|}{ Antepartum hemorrhage } \\
\hline Yes & $30(37.5)$ & $37(11.6)$ & \multirow{2}{*}{$4.5(2.58-8.09)$} & \multirow{2}{*}{0.000} \\
\hline No & $50(62.5)$ & $283(88.4)$ & & \\
\hline \multicolumn{5}{|l|}{ Infection } \\
\hline Yes & $25(31.3)$ & $183(57.2)$ & \multirow{2}{*}{$0.34(0.2-0.57)$} & \multirow{2}{*}{0.000} \\
\hline No & $55(68.7)$ & $137(42.8)$ & & \\
\hline \multicolumn{5}{|c|}{ Hypertension disorders } \\
\hline Yes & $2(2.5)$ & $31(9.7)$ & \multirow{2}{*}{$2.78(1.01-6.8)$} & \multirow{2}{*}{0.020} \\
\hline No & $78(97.5)$ & $289(90.3)$ & & \\
\hline \multicolumn{5}{|c|}{ Sickle cell disease } \\
\hline Yes & $1(1.2)$ & $11(3.4)$ & \multirow{2}{*}{$0.36(0.02-2.13)$} & \multirow{2}{*}{0.270} \\
\hline No & $79(98.8)$ & $309(96.6)$ & & \\
\hline \multicolumn{5}{|c|}{ HIV infection } \\
\hline Yes & $5(6.2)$ & $12(3.8)$ & \multirow{2}{*}{$1.71(0.53-4.91)$} & \multirow{2}{*}{0.240} \\
\hline No & $75(93.8)$ & $308(96.2)$ & & \\
\hline \multicolumn{5}{|l|}{ Diabete } \\
\hline Yes & $0(0)$ & $1(0.3)$ & \multirow{2}{*}{$0(0-76)$} & \multirow{2}{*}{0.800} \\
\hline No & $80(100)$ & $319(99.7)$ & & \\
\hline
\end{tabular}

Table 4: Distribution of participants according to fetal characteristic.

\begin{tabular}{|c|c|c|c|c|}
\hline Variables & Case $\mathbf{N}=\mathbf{8 0}$ n (\%) & Control N=320 n (\%) & OR (IC $95 \%$ ) & P-value \\
\hline \multicolumn{5}{|l|}{ Sex } \\
\hline Male & $36(45)$ & $116(36.3)$ & \multirow{2}{*}{$1.44(0.87-2.36)$} & \multirow{2}{*}{0.100} \\
\hline Female & $44(55)$ & $204(63.8)$ & & \\
\hline \multicolumn{5}{|c|}{ Multiple gestation } \\
\hline Yes & $4(5)$ & $22(6.9)$ & \multirow{2}{*}{$0.71(0.2-2.01)$} & \multirow{2}{*}{0.380} \\
\hline No & $76(95)$ & $298(93.1)$ & & \\
\hline \multicolumn{5}{|c|}{ Intrauterin growth restriction } \\
\hline Yes & $9(11.3)$ & $43(13.4)$ & \multirow{2}{*}{$0.82(0.36-1.71)$} & \multirow{2}{*}{0.380} \\
\hline No & $71(88.8)$ & $277(86.6)$ & & \\
\hline \multicolumn{5}{|c|}{ Fetal malformations } \\
\hline Yes & $4(5)$ & $6(1.9)$ & \multirow{2}{*}{$2.75(0.67-10.27)$} & \multirow{2}{*}{0.120} \\
\hline No & $76(95)$ & $314(98.1)$ & & \\
\hline
\end{tabular}

\section{DISCUSSION}

In our study, age greater than 30 years independently constituted a risk of developing fetal death in utero, despite the fact that this result was not statistically significant. This corroborates the results of several authors some of which were much more restrictive at 35 years. ${ }^{6}$ This could be explained by the fact that, with aging, there is a resurgence of chronic pathologies such as hypertension, diabetes. These non-communicable diseases are deleterious to pregnancy when they are poorly controlled. The maternal age increases the risk of chromosomal abnormalities and fetus malformations which can lead to the death of the fetus. ${ }^{7}$ 
Regarding marital status, in our study, singles were the most represented with no statistically significant difference in the two groups. Several studies corroborate our findings that unmarried women are at greater risk of developing fetal death in utero. ${ }^{6,7}$ This may be explained by the fact that single women often do not have the financial means to go to a health facility to follow up their pregnancies because in our health system, cares are not free of charge in a setting where the general population is poor. This study shows that most of the women were householders in the case group and students in the control group; Householders and students do not have any financial income. Married women receive financial assistance from their spouses, resulting in good medical adherence and good follow-up of pregnancy. This poor follow-up of pregnancy among unmarried women is characterized by a delay in the initiation of prenatal consultations, a lower incidence of prenatal consultations, and a low rate of taking iron supplementation. ${ }^{8}$

Moreover, in some Cameroonian cultures, pregnancy in a single woman is considered a failure by the parents and the woman is often the victim of stigmatization. The pregnant single woman will hide her pregnancy to avoid rejection by parents and other members of the community. Some women will try to abort by taking medicines to kill the fetus. The majority of our study population had a low level of education. This can explained the lack of understanding the counseling from health providers.

In terms of the gyneco-obstetric profile, parity greater than 5 is a risk factor for fetal death in utero. This corroborates the results found in other studies. ${ }^{6,9}$ This is explained by the fact that the multiparity is associated with a advanced age and thus the increase in the frequency of fetal malformations and chronic pathologies. On the other hand, it is also associated with an increase in the incidence of pathologies such as placenta prævia, abruption placenta which may compromise placenta perfusion. ${ }^{9,10}$

The Antepartum hemorrhage is a risk factor for in utero fetal death. This corroborates the findings of other authors. ${ }^{6,11,12}$ This result can be explained by the fact that the bleeding is responsible for the decrease of blood pressure and the hemoglobin level, which leads to a decrease in placental utero perfusion and also the possibility in some cases of the presence of a retro placental hematoma which reduces materno-fetal exchanges. This results in a decrease in fetal perfusion and therefore a possibility of fetal death in utero.

Hypertension disorders double the risk of IUFD. This is in line with the fact that several studies carried out the notion of hypertension in pregnancy constitutes an independent risk factor for fetal death in utero. ${ }^{11,12}$ This is due to the placental insufficiency of vascular origin and also to the frequency of retroplacental haematomas resulting in a decrease of fetal perfusion. ${ }^{13,14}$

In our study, a history of spontaneous abortion was a protective factor of IUFD. This situation can be explained by the facts that after the occurrence of spontaneous abortions, the women feared to lose their pregnancy again, therefore will observe preventive and curative measures for a good follow-up of their pregnancy.

Infectious pathology during pregnancy was not a risk factor for fetal death in utero. This is contrary to the findings of other authors. ${ }^{5,15}$ This can be explained by the poor health information system in our country because the care given to the patients are not always recorded by the providers of care in the prenatal follow-up and the data concerning the pathologies of the patients are not computerized access.

Authors did not find any risk factors related to the fetus. This can be explained by the fact that the fetuses are often in advanced maceration, making the macroscopic examination difficult. Moreover, because of the insufficient level of the infrastructures in our low income area, bacteriological samples of the placenta and the membranes are not carried out, neither the microscopic examination of the placenta nor the autopsy of the fetus and even searching for chromosomal abnormalities are not done.

The limitation of this study was the type of study being case-control, exposes to the risks of memory bias in the witnesses and the lack of information in the files of the patients. Due to insufficient technical facilities in our health facilities, examination of the placenta and fetus is not possible.

\section{CONCLUSION}

The main risk factors for IUFD identified in our study are maternal age greater than 30 years, hypertension, antepartal haemorrhage, multiparity, and the household profession. Any pregnant woman who has one of these factors should be follow-up closely during pregnancy with a weekly assessment of fetal well-being by the $28^{\text {th }}$ week.

\section{Funding: No funding sources \\ Conflict of interest: None declared \\ Ethical approval: The study was approved by the Institutional Ethics Committee}

\section{REFERENCES}

1. Blencowe H, Cousens S, Jassir FB, Say L, Chou D, Mathers C, et al. Stillbirth epidemiology investigator group. National, regional, and worldwide estimates of stillbirth rates in 2015, with trends from 2000: a systematic analysis. Lancet Glob Heal. 2016;4(2):98108. 
2. Cousens S, Blencowe H, Stanton C, Chou D, Ahmed S, Steinhardt L, et al. National, regional, and worldwide estimates of stillbirth rates in 2009 with trends since 1995: a systematic analysis. Lancet. 2011;377 (9774):1319-30.

3. Quibel T, Bultez T, Nizard J, Subtil. Morts fœtales in utéro. Journal de gynécologie obstétrique et biologie de la reproduction. 2014;43:883-907.

4. Akolekar R, Tokunaka M, Ortega N. Prediction of stillbirth from maternal factors, fotal biometry and utérine artery doppler. Ultrasound Obstet Gynecol. 2016;48(5):631-5.

5. Flenady V, Middleton P, smith GC, Dube W. Still birth: the way forward in highincome countries. Lancet's still births series steering committee. Lancet's still births series steering committee. Lancet. 2011;377:1703-17.

6. AliyuMh, Salihu HM, Keith Lg, Ehiri JE. Extrem parity and the risk of stillbirth. Obstet Gynecol. 2005; 106:446-53.

7. Andriamandimbison Z, Randriambololona DMA, Rasoanandrianina BS. Étiologies de la mort foetale in utero: à propos de 225 cas à l'hôpital de Befelatanana Madagascar: Médecine et Sante' Tropicale. 2013;23:78-82.

8. Charle V, Fatimata L. Grossesse chez la célibataire à Niamey. Afr J Reprod Health. 2001;5(2):98-104.

9. Cabrol D, Pons JC, Goffinet F. Mort foetale in utero. Traité d'Obstétrique. Paris: Médecine-Science Flammarion. 2003:353-8.
10. Conde-Argudelo A, Belizan JM, Diaz-Rosselo JL. Epidemiology of fetal death in Latin America. Acta Obstetrica Gynecol Scand. 2000;79:371-8.

11. Ashish KC, Viktoria N, Wrammert J, Uwe, Ewald. Risk factors for antepartum stillbirth: a case-control study in Nepal. BMC Pregn Childbirth. 2015;15:146.

12. Sonal A, Nandita K. Aetiological classification of stillbirth; a case control study. J Obstet Gynaecol India. 2016;66(6):420-5.

13. Uzan M, Haddad B, Uzan S. Hematome retroplacentaire. Encycl Med Chir, Paris: Elsevier, Obstet. 1995;5-071-A-10.

14. Nahar S, Rahman A, Nasreen HE. Factors influencing stillbirth in Bangladesh: a case-control study. Paediatric Perinatal Epidemiol. 2013;27:15864.

15. Tantbirojn P, Saleemunddin A, Sirois K, Crum CP, Boyd TK. Cross abnormalities of the umbilical cord: related placental histology and clinical significance. Placenta. 2009;30:10838.

Cite this article as: Momo RJT, Fouedjio JH, Fouelifack FY, Mbu RE. Risk factors of intrauterine fetal death: a case control study at the maternity of Yaoundé central hospital. Int J Reprod Contracept Obstet Gynecol 2019;8:2149-54. 